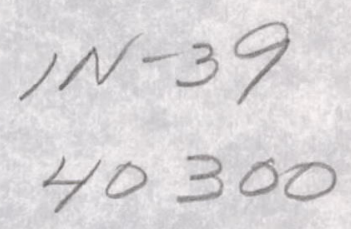

NASA Technical Memorandum 106852

\title{
Reliability Analysis of Uniaxially Ground Brittle Materials
}

Jonathan A. Salem and Noel N. Nemeth

Lewis Research Center

Cleveland, Ohio

Lynn M. Powers and Sung R. Choi

Cleveland State University

Cleveland, Ohio

Prepared for the

Turbo Expo 1995

sponsored by the American Society of Mechanical Engineers

Houston, Texas, June 5-8, 1995

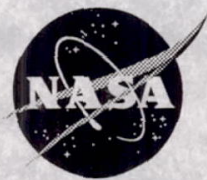

National Aeronautics and Space Administration

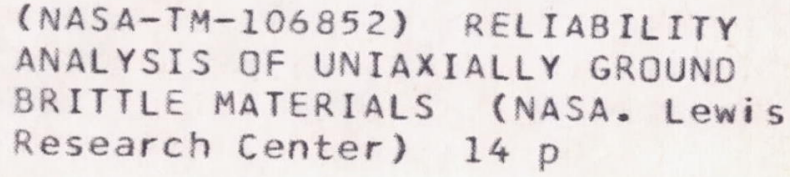




\title{
RELIABILITY ANALYSIS OF UNIAXIALLY GROUND BRITTLE MATERIALS
}

\author{
Jonathan A. Salem and Noel N. Nemeth \\ NASA Lewis Research Center \\ Cleveland, Ohio \\ Lynn M. Powers and Sung R. Choi \\ Department of Civil Engineering \\ Cleveland State University \\ Cleveland, Ohio
}

\begin{abstract}
The fast fracture strength distribution of uniaxially ground, alpha silicon carbide was investigated as a function of grinding angle relative to the principal stress direction in flexure. Both as-ground and ground/annealed surfaces were investigated. The resulting flexural strength distributions were used to verify reliability models and predict the strength distribution of larger plate specimens tested in biaxial flexure. Complete fractography was done on the specimens. Failures occurred from agglomerates, machining cracks, or hybrid flaws that consisted of a machining crack located at a processing agglomerate. Annealing eliminated failures due to machining damage. Reliability analyses were performed using two and three parameter Weibull and Batdorf methodologies. The Weibull size effect was demonstrated for machining flaws. Mixed mode reliability models reasonably predicted the strength distributions of uniaxial flexure and biaxial plate specimens.
\end{abstract}

$\begin{array}{ll}\text { NOMENCLATURE } \\ \mathrm{A} & \text { surface area } \\ \overline{\mathrm{C}} & \text { Shetty's constant in mixed-mode fracture criterion } \\ \mathrm{H} & \text { step function } \\ \mathrm{h} & \text { thickness } \\ \mathrm{K} & \text { stress intensity factor } \\ \mathrm{k} & \text { crack density coefficient } \\ \mathrm{k}_{\mathrm{BS}} & \text { Batdorf crack density coefficient for } \\ & \text { surface distributed flaws } \\ \mathrm{l} & \text { direction cosine; } 1=\text { cos } \alpha \\ \mathrm{m} & \text { Weibull modulus (shape parameter), or } \\ & \text { direction cosine; } \mathrm{m}=\text { sin } \alpha \\ \mathrm{m}_{\mathrm{S}} & \text { Weibull modulus for surface flaws } \\ \mathrm{P} & \text { load } \\ \mathrm{P}_{\mathrm{f}} & \text { cumulative failure probability } \\ \mathrm{R}_{\mathrm{S}} & \text { diagonal half length } \\ \mathrm{r} & \text { radius } \\ \mathrm{x}, \mathrm{y}, \mathrm{z} & \text { Cartesian coordinate directions }\end{array}$

$\mathrm{Y} \quad$ crack geometry factor

$\alpha \quad$ angle between $\sigma_{\mathrm{n}}$ and the stress $\sigma_{1}$

$\eta \quad$ crack density function

$\pi \quad 3.1416$

$v \quad$ Poisson's ratio

$\sigma \quad$ applied stress distribution

$\sigma_{\text {cr }} \quad$ critical mode I strength of a crack

$\sigma_{\mathrm{e}} \quad$ effective (equivalent) mode I stress on a crack

$\sigma_{\mathrm{o}} \quad$ Weibull scale parameter

$\sigma_{\mathrm{u}} \quad$ threshold strength

$\sigma_{1}, \sigma_{2}, \sigma_{3}$ tensor stress components; principal stresses

$\left(\sigma_{1} \geq \sigma_{2} \geq \sigma_{3}\right)$

$\tau \quad$ shear stress acting on oblique plane whose normal is determined by angle $\alpha$

$\Psi \quad$ spatial location ( $\mathrm{x}, \mathrm{y}, \mathrm{z})$ and orientation $(\alpha)$ in a component

$\omega \quad$ angle in two-dimensional principal stress space for which

$$
\sigma_{\mathrm{e}} \geq \sigma_{\mathrm{cr}}
$$

Subscripts:

$\begin{array}{ll}\text { B } & \text { Batdorf } \\ \text { cr } & \text { critical } \\ \text { e,ef } & \text { effective } \\ \text { eq } & \text { equivalent } \\ \text { f } & \text { failure; fracture } \\ \text { I } & \text { crack opening mode } \\ \text { II } & \text { crack sliding mode } \\ \text { III } & \text { crack tearing mode } \\ \text { i } & \text { inside } \\ \text { max } & \text { maximum } \\ \text { n } & \text { normal; normal stress averaging } \\ \text { o } & \text { outside } \\ \text { S } & \text { surface } \\ \text { u } & \text { threshold } \\ \theta & \text { characteristic }\end{array}$

Superscripts: normalized quantity 


\section{INTRODUCTION}

A basic requirement for reliability analysis of components made from brittle materials is a knowledge of the strength distribution of the flaws that will induce failure. Two basic types of strength limiting flaws are encountered: surface defects and volumetric defects. Volumetric defects include large grains, pores, agglomerates coarse precipitates and inclusions, while surface defects could include exposed volume defects (e.g. a pore machined open) and machining or handling damage occurring during fabrication ${ }^{(1)}$.

In some cases the failure inducing flaws are distributed randomly and thus the strength distribution is independent of orientation and simple, uniaxial test data can be used in conjunction with an isotropic model. However, for components made by processes, such as extrusion, which induce texture, a bias in the distribution of processing flaws will exist. Also, components finished by surface grinding will also contain machining damage in the form of cracks that are oriented parallel and transverse to the grinding direction. Fortunately for the designer, processes typically used to make larger, three dimensional components do not induce strong textures. However, uniaxial grinding is used for finishing of components and to make test specimens for strength measurements.

The strength of a ceramic material is typically measured in accordance with ASTM C1161 ${ }^{(1)}$ which specifies that machined specimens be ground uniaxially in the longitudinal direction and tested so that the maximum principal stress is longitudinal. Such a grinding process typically induces minimal damage in the transverse direction, but significant damage in the longitudinal direction, resulting in an anisotropic flaw distribution on the surface of the specimen. Since the beam is stressed longitudinally, such a preparation is typically sufficient to avoid failures from machining damage, and result in measurements that are representative of strength limiting defects associated with the materials processing (e.g. agglomerates, inclusions, pores, coarse grains, etc). However, structural components and multiaxial test specimens are subjected to multiaxial stresses and thus are sensitive to planer flaws with the crack plane oriented in any direction.

Thus, if uniaxial grinding that imparts damage in one direction is used or if anisotropic damage occurs, component design and life prediction methods must account for such anisotropies. The objective of this work is to measure the effect of unidirectional grinding on the strength distribution of a ceramic material under various loading conditions and determine if adequate component reliability models could be formulated.

The fast-fracture strength of a sintered alpha silicon carbide was measured in four-point flexure with the principal stress oriented at angles between 0 and $90^{\circ}$ relative to the grinding direction. Also, uniaxially ground plate specimens were loaded in biaxial flexure. Finally, flexure bar specimens were tested in an annealed condition to determine if the machining damage could be healed. Modeling of the strength distributions was done with two and three parameter Weibull models and shear sensitive and insensitive cracks. Alpha silicon carbide was chosen because it exhibits a very low fracture toughness, no crack growth resistance, high elastic modulus and a very low susceptibility to slow crack growth. Such properties should make this an ideal ceramic for the verification of fast fracture reliability models and codes.

\section{EXPERIMENTAL METHOD}

The material used in this study was a commercially available sintered alpha silicon carbide (Carborundum's Hexoloy) processed in the form of 25 by 25 by $42 \mathrm{~mm}$ billets. Several sets of plates were ground from the billets and finished by 320 grit diamond grinding one face of the plates at angles ranging from 0 to $90^{\circ}$ relative to the plate edge. Flexure beams were then cut from the plates. Beams with a given grinding angle were cut from a random selection of plates in order to block the effects of billet and location on the test results. The specimen edges along the tensile surface were beveled by hand to eliminate spurious edge failures. The specimens nominally measured 2 by 3 by $25 \mathrm{~mm}$ in height, width and length, and were tested in four-point flexure with inner and outer spans of 8 and $20 \mathrm{~mm}$, respectively, at room temperature with a stroke rate of $0.05 \mathrm{~mm} / \mathrm{min}$. The rollers of the test fixture were free to roll and the upper span was free to articulate relative to the lower span. A minimum of 30 specimens were tested per condition.

In order to determine if the deleterious effects of grinding damage could be negated, a group of 0 and $90^{\circ}$ specimens were annealed at $1200^{\circ} \mathrm{C}$ for two hours in air prior to testing.

\section{RESULTS AND DISCUSSION}

\section{Strength Distributions}

Specimen strength as a function of grinding angle relative to the longitudinal direction is shown in Figure 1 and summarized in Table 1. The average strength and standard deviation decrease continually as the angle increases with exception of the 30 and $45^{\circ}$ data which are quite similar. Annealing does not significantly change the average strength of specimens ground at $0^{\circ}$ (i.e. longitudinally). However, specimens ground at $90^{\circ}$ (i.e transversely) and annealed exhibited strengths not significantly different from those of the 0 annealed and $0^{\circ}$ as-ground specimens. This implies that significant, strength limiting damage relative to the processing flaws, for this material, only exists parallel to the grinding direction (such that specimen strength is effected when loading is transverse to the grinding direction), and that annealing eliminates the grinding damage but does not significantly enhance the strength of $0^{\circ}$ ground specimens.

Weibull plots of the annealed and as-ground specimens are shown in Figures 2(a) - 2(d). The Weibull modulus continuously increases with increasing grinding angle while the characteristic strength decreases. Annealing does not significantly change the distribution parameters of $0^{\circ}$ ground specimens, and annealing appears to totally heal machining damage associated with the $90^{\circ}$ ground specimens. As all these data sets lied will within each others $90 \%$ confidence intervals, the annealed specimen data and the $0^{\circ}$ as-ground data were pooled.

\section{Fractography}

Fractographic analysis is a necessary aspect of reliability analysis in order to determine whether surface, volume, or combined (surface and volume) flaw reliability analysis should be performed, and if flaws of different processing sources are present. Fractography to determine the sources and locations of failure was done in 
accordance with military handbook procedures ${ }^{(2)}$. The results are summarized in Table 2. Three types of flaws were encountered: processing flaws, machining cracks and hybrid flaws. The processing flaws that induced failure were agglomerates located at the tensile surface (i.e. cut open during machining) or located slightly below (within one flaw diameter). Occasionally ( $<10 \%$ of the time) failure occurred from agglomerates located greater than the flaw diameter below the surface. These failures are classified as 'volume' in Table 2. Machining cracks were semi-elliptical and cartiodal cracks typically oriented parallel to the grinding direction. Hybrid flaws were defined as a machining crack connected with an agglomerate. It is not clear if hybrids constituted a distinct failure population and their overall numbers are relatively small. The various type of origins are shown in Figures 3 and 4 . Although both the processing and machining flaws were complex shapes, the processing flaws are typically larger in overall size, indicating a bluntness relative to the machining flaws.

Annealed specimens and $0^{\circ}$ as-ground specimens appear to fail from surface and near surface processing agglomerates, while 30 , 45,60 , and $90^{\circ}$ as-ground specimens fail from either surface and near surface agglomerates, machining cracks or hybrid flaws. At lower grinding angles final fracture of hybrids occurred from the agglomerate and at higher angles fracture occurred from the machining crack (i.e. the river markings point to either the agglomerate or the machining crack, respectively). As the grinding angle increased the number of agglomerates associated with failure decreased.

Note (Figure 3(b)) how the crack path from a $30^{\circ}$ machining flaw is initially parallel to the grinding direction and gradually turns normal to the principal stress direction on one side of the flaw, but not on the other. The river marks indicated that fracture initiated from the deepest point of the crack and followed the crack plane (coplanar extension) to the surface where it gradually turned normal to the applied stress. Evidently, mixed stress intensity modes exist during such failures, but the amount of extension under mixed modes is unclear. Also, the macroscopic fracture plane can occasionally be observed to jog parallel to the grinding direction in regions well away from the origin. A machining crack can typically be observed at such jogs.

Note also (Figure 4) that the mirror of the hybrid flaw centers on the machining crack and that it dominated failure. Coplanar extension is not apparent at the surface, however, it is apparent in the interior.

\section{Modeling of the Strength Distribution}

As a result of different flaw populations (agglomerate and machining flaw) being simultaneously present in any given specimen, the contribution of each flaw population to the cumulative failure probability of the specimen must be considered. The survival probability of the specimen from these simultaneously present (concurrent) flaw populations is the product of the survival probabilities of the specimen from each flaw population considered separately. Weibull plots of the concurrent populations for 30,45 , 60 and $90^{\circ}$ grinding angles are shown in Figure 5. Note that as the grinding angle increases, the frequency of failure at machining flaws increases and that they populate the upper end of the overall distributions. No distinct pattern for the distribution of hybrid flaws shows up in Figure 5.

Two and three parameter Weibull formulations were used to represent the strength distribution. Response of the flaw population to multiaxial stresses was predicted with shear sensitive and insensitive flaw (Batdorf) models. These models were modified such that anisotropic flaw orientation or allowing a threshold/truncation stress was possible. The overall strength distribution was modeled as a bimodal distribution of agglomerate flaws and machining flaws. The effects of hybrid and volume flaws were not considered, as these populations were small.

\section{Agglomerate Flaws}

The Batdorf $\mathrm{f}^{(3,4,5)}$ theory was used to describe the strength response from the ground surface. The agglomerate flaws were modeled as randomly distributed and randomly oriented microcracks with the exception that the crack plane was perpendicular to the surface. The probability of failure for a ceramic component using the Batdorf model for such surface flaws is ${ }^{(4)}$

$$
P_{f s}=1-\exp \left\{-\int_{A}\left[\int_{\sigma_{u}}^{\sigma_{e_{\max }}} \frac{\omega}{2 \pi} \frac{d \eta_{s}\left(\sigma_{c r}\right)}{d \sigma_{c r}} d \sigma_{c r}\right] d A\right\}
$$

where $A$ is the surface area, $\eta_{S}$ is the crack density function, $\sigma_{e_{\max }}$ is the maximum value of effective stress, $\sigma_{\mathrm{e}}$, for all values of spatial angle $\Psi$, and $\omega$ is the arc length of an angle $\alpha$ projected onto a unit radius circle in stress space containing all of the crack orientations for which the effective stress is greater than or equal to the critical mode I stress, $\sigma_{\mathrm{cr}}$. The integration limit $\sigma_{\mathrm{u}}$ represents a threshold value below which no failures exist. This effectively truncates the statistical strength distribution and is similar to a proof test. However, in this case the truncation may occur naturally or result from processing controls on the maximum flaw size. The crack density distribution is a function of the critical stress distribution. For surface flaw analysis, the crack density function is expressed as

$$
\eta_{\mathrm{s}}\left(\sigma_{\mathrm{cr}}(\Psi)\right)=\mathrm{k}_{\mathrm{BS}} \sigma_{\mathrm{cr}}^{\mathrm{m}_{\mathrm{s}}}
$$

where $\mathrm{k}_{\mathrm{BS}}$ and $\mathrm{m}_{\mathrm{S}}$ are material constants. The flaw orientation function is expressed as<smiles>CC(C)C(C=O)OC(=O)O</smiles> 
where

$$
H\left(\sigma_{\mathrm{e}}, \sigma_{\mathrm{cr}}\right)= \begin{cases}1 & \sigma_{\mathrm{e}} \geq \sigma_{\mathrm{cr}} \\ 0 & \sigma_{\mathrm{e}}<\sigma_{\mathrm{cr}}\end{cases}
$$

Equation (3) represents the fraction of critically oriented flaws over all possible flaw orientations. The equivalent stress $\sigma_{\mathrm{e}}$ is dependent on the appropriate fracture criterion and crack shape. Equation (1) can be simplified by performing the integration of $\sigma_{\mathrm{cr}}{ }^{(5)}$ yielding the probability of failure for surface flaw analysis as

$$
\begin{array}{r}
P_{f s}=1-\exp \left[-\frac{k_{B S}}{2 \pi} \int_{A} \int_{0}^{2 \pi}\left[\sigma_{e}^{m_{s}}(\Psi)-\sigma_{u}^{m_{s}}\right]\right. \\
H\left(\sigma_{e}, \sigma_{u}\right) d \alpha d A
\end{array}
$$

When the threshold stress, $\sigma_{u}$, is zero then equation (4) reduces to a two-parameter Weibull type distribution for a specified stress state.

Assuming that small crack-like imperfections control the failure, the material strength in multiaxial stress states can be correlated to the effects of mixed-mode loading on the individual cracks. $^{(4,5)}$ Shetty ${ }^{(6)}$ developed a simple equation describing the ability of a crack to extend under the combined actions of a normal and shear load on the crack face using an empirically determined parameter, $\overline{\mathrm{C}}$. For a semicircular crack, the equation for the effective stress is ${ }^{(7)}$

$$
\sigma_{\mathrm{e}}=\frac{1}{2}\left[\sigma_{\mathrm{n}}+\sqrt{\sigma_{\mathrm{n}}^{2}+3.301\left(\frac{\tau}{\overline{\mathrm{C}}}\right)^{2}}\right]
$$

where $\sigma_{n}$ is the normal stress on the flaw and $\tau$ is the shear stress on the flaw. The Batdorf methodology used herein is normalized to uniaxial specimen rupture data ${ }^{(3,4)}$. Therefore, the choice of $\overline{\mathrm{C}}$ does not effect the failure probability predictions for the flexure bar specimens. For the agglomerates a value of $\overline{\mathrm{C}}$ of 1.0 is assumed (to be consistent with the results from grinding damage). Areference frame relative to machining direction is used to define the normal and shear stress components. The normal and shear stress components are computed from

$$
\sigma_{\mathrm{n}}=1^{2} \sigma_{\mathrm{x}}+\mathrm{m}^{2} \sigma_{\mathrm{y}}+2 \operatorname{lm} \tau_{\mathrm{xy}}
$$

and

$$
\tau^{2}=\left(1 \sigma_{x}+m \tau_{x y}\right)^{2}+\left(1 \tau_{x y}+m \sigma_{y}\right)^{2}-\sigma_{n}^{2}
$$

where 1 , and $\mathrm{m}$ are the direction cosines

$$
\begin{aligned}
& 1=\cos \alpha \\
& m=\sin \alpha
\end{aligned}
$$

Comparison of the Batdorf to the following form of the three parameter Weibull distribution can be performed

$\mathrm{P}_{\mathrm{fs}}=1-\exp \left\{-\int_{\mathrm{A}}\left[\left(\frac{\sigma_{1}-\sigma_{\mathrm{u}}}{\sigma_{\theta \mathrm{S}}}\right)^{\mathrm{m}_{\mathrm{s}}}+\left(\frac{\sigma_{2}-\sigma_{\mathrm{u}}}{\sigma_{\theta \mathrm{S}}}\right)^{\mathrm{m}_{\mathrm{s}}}\right] \mathrm{dA}\right\}$

where $\sigma_{1}$ and $\sigma_{2}$ are the principal stresses, and $\sigma_{\theta \mathrm{S}}$ is the characteristic strength.

\section{Machining Flaws}

Richerson $^{(8)}$ has described machining flaws as consisting of populations of median (longitudinal) cracks, lateral cracks and radial cracks (transverse). The longitudinal cracks are parallel to the grinding groove and perpendicular to the surface of the material. The radial cracks are perpendicular to the longitudinal cracks and lateral cracks run parallel to, but branch off at some angle from the grinding groove. As the only strength limiting flaws induced by unidirectional grinding were observed to be oriented parallel to the grinding direction, the flaw distribution, for modeling purposes, can be treated as an anisotropic distribution. The fact that all the strength limiting machining cracks are parallel to each other eliminates the need for the orientation function $\omega / 2 \pi$ in equation (3) and equation (1) is then rewritten as

$\mathrm{P}_{\mathrm{fS}}=1-\exp \left\{-\int_{\mathrm{A}}\left[\int_{\sigma_{\mathrm{u}}}^{\sigma_{\mathrm{e}_{\max }}} \mathrm{H}\left(\sigma_{\mathrm{e}}, \sigma_{\mathrm{cr}}\right) \frac{\mathrm{d} \eta_{\mathrm{S}}\left(\sigma_{\mathrm{cr}}\right)}{\mathrm{d} \sigma_{\mathrm{cr}}} \mathrm{d} \sigma_{\mathrm{cr}}\right] \mathrm{dA}\right\}$

Analogous to the formulation shown in equation (4), equation (10) can be simplified, yielding

$$
P_{f S}=1-\exp \left[-k_{B S} \int_{A}\left(\sigma_{e}^{m_{s}}-\sigma_{u}^{m_{s}}\right) d A\right]
$$

where $\sigma_{\mathrm{e}}$ represents the effective stress on the longitudinal machining flaw. The threshold strength $\sigma_{\mathrm{u}}$ in this case may possibly be related to the largest grit size of the grinding wheel. Since grinding particle sizes are screened, this may translate to a maximum flaw size that can be induced in the material surface.

As the machining cracks tended to be semielliptical, a semicircular flaw geometry was assumed here and equation (5) applied. A reference frame relative to grinding direction was used to define the normal and shear stress components.

Since the machining cracks are oriented in one direction, comparison to a three parameter Weibull distribution is feasible 


$$
P_{f S}=1-\exp \left\{-\int_{A}\left(\frac{\sigma_{e}-\sigma_{u}}{\sigma_{\theta S}}\right)^{m_{S}} d A\right\}
$$

where $\sigma_{e}$ is the effective stress in equation (5), and $\sigma_{\theta S}$ is the characteristic strength.

\section{Other Modeling Considerations}

As a result of the agglomerates and machining flaws being simultaneously active, a multi-modal distribution function was used to describe the overall probability of failure

$$
\mathrm{P}_{\mathrm{fS}_{\text {total }}}=1-\left(1-\mathrm{P}_{\mathrm{fS}_{\text {agglomerate }}}\right)\left(1-\mathrm{P}_{\mathrm{fS}_{\text {machining }}}\right)
$$

The finite element method or a simple numerical procedure were used for stress analysis as they enable discretization of a component or specimen into incremental volume (and surface) elements from which the probability of failure (i.e. eq. (13)) can be evaluated. Either the Gaussian integration points of the elements or, optionally, the element centroids can be used to numerically evaluate the stressarea integrals $^{(9)}$ in equations (4), (9), (11), and (12). Assuming that the probability of survival for each element is a mutually independent event, the overall component reliability is then the product of all the calculated element (or subelement) survival probabilities.

A simple model of one half of the ground tensile surface of the flexure bar was prepared for the strength predictions. The model consisted of a single sub-area between the inner loading points (where a constant stress exists) and 600 equispaced sub-areas between the inner and outer loading point to capture the linearly varying stress along the specimen length. Each sub-area was assumed to have a constant stress state. This model is analogous in effect to a finite element model of the upper tensile surface of the specimen where each sub-area would correspond to a surface element and the element centriodal stress is used in the reliability analysis.

The bar surface stress distribution and preceding equations were used to predict the behavior of the 30,45 , and 60 degree orientations based on the best fit distributions (maximum likelihood estimator) of the 0 and 90 degree data. The resulting distributions are shown in Figure 6 compared to the actual data for several cases. As shown in the figure, the two parameter model appears to fit the data poorly at the lower probabilities of failure.

Both the shear sensitive three parameter and truncation distribution models are better fits to the data, however, no specific justification for the lower strength boundary can be given. Although truncation of the distribution may be due to largest grit size, this was not proven here. The shear insensitive models did not correlate well to the data. The shear sensitive models use a Shetty shear sensitivity coefficient that ranged in value between 1.00 and 1.05 (therefore approximately 1.0).

\section{Prediction of Strength Distributions Resulting from Multiaxial Stresses}

The previous results were derived from loading conditions resulting in a uniaxial stress state, however, components are frequently subjected to multiaxial stresses. Thus, a second set of plates were ground and tested in biaxial flexure via ring-on-ring loading. As both the specific grinding damage and agglomerates within these plates were expected to control strength, uniaxial $\left(90^{\circ}\right)$ specimens were also cut from these plates and tested in either fourpoint flexure as described above or in three-point flexure with a 20 mm support. In order to test the capability of the models to account for area changes, multiaxial stresses and machining damage along one axis, a quarter symmetry, finite element model (Figure 7(a)) of the biaxial specimen was made and the output interfaced with a version of the CARES ${ }^{(7)}$ code containing the previously described models. The finite element model was prepared using MSC/ NASTRAN and consisted of 200 solid elements (a single element spanned the plate thickness) and 200 shell elements. The shell elements were attached to the tensile surface of the plate model and had negligible thickness and membrane properties only. The reliability of the plate was determined from the stress and surface area output of the shell elements. Ring-on-ring load induces an equibiaxial stress state within the inner ring. The fracture stress, $\sigma_{f}$, at the specimen center was computed as a function of the fracture load, $\mathrm{P}$, and is given by $(10)$

$$
\sigma_{f}=\frac{3 P}{4 \pi h^{2}}\left[2(1+v) \ln \left(\frac{r_{o}}{r_{i}}\right)+\frac{(1-v)\left(r_{o}^{2}-r_{i}^{2}\right)}{R_{S}^{2}}\right]
$$

where $R_{S}$ is the diagonal half length, $r_{i}$ is the inner radius, $r_{0}$ is the outer radius, $h$ is the thickness, and $v$ is Poisson's ratio.

The results are summarized in Table 3 and shown in Figure 7(b). A distinct effect of scale can be seen when machining damage controls the uniaxial specimen failure. Note that the Weibull parameters of the second set of $90^{\circ}$ specimens were significantly different (exceeds $90 \%$ confidence bounds) from those of the first set (Table 1), even though the same grinding specification was used. A more stringent control, other than just the grit size and removal depth specified in ASTM C1161, may be required to adequately control damage parallel to the longitudinal direction. Prediction of the plate failure distribution and the three-point bend specimens distribution based on the four-point data is shown by the dashed lines in Figure 7(b) for a two parameter, shear sensitive model. Use of a shear insensitive model did not substantially change the results, as the flaws experience little mixed mode loading for this specimen configuration. Goodness-of-fit tests indicated that the 2-parameter model gave a slightly better fit than a three parameter model. This fact does not rule out the existence of a threshold strength, but it is not as clearly manifested as before (and therefore not investigated). From a design point of view, a two parameter model will give a more conservative failure probability than a three parameter model. 
A threshold strength must be clearly and consistently demonstrated for the purpose of a safe design. These results firmly establish that a statistical approach incorporating multiaxial failure criterion must be used as a basis for designing ceramic components. Variations between sample sets must either be resolved by improved control on the machining process, or accounted for by sampling multiple specimen sets. Ultimately, more research is needed in this area.

\section{CONCLUSIONS}

The strength distribution of silicon carbide was found to be a function of grinding orientation for a typical uniaxial grinding procedure (e.g. ASTM C1161). However, annealing greatly reduced or eliminated the effect of grinding orientation on strength. Annealing did not increase the strength of longitudinally ground flexure specimens. The Weibull size effect was exhibited by the asground specimens. Annealed and longitudinally ground specimens typically fail from surface and near surface agglomerates while transversely ground specimens predominantly fail from machining cracks.

Truncated distribution and three-parameter models appear to best approximate the first experimental data generated in this work (beams ground at various angles). The effects of mixed-mode fracture of machining cracks was adequately predicted by the models for the larger angles of orientation $\left(>30^{\circ}\right)$. Strength data for low grinding angles showed some deviation from predicted results, possibly reflecting damage to the agglomerate flaws during the machining process. However, fractography did not detect this damage. For the second data set (plates and beams cut from plates), the uniaxial data was reasonably fit with a two parameter distribution and a two parameter model accurately predicted the biaxial strength distribution.

\section{ACKNOWLEDGEMENTS}

The authors would like to thank Ben Willard for help with the experimental work. This research was sponsored in part by the Ceramic Technology Project, DOE Office of Transportation Technologies, under contract DE-AC05-840R21400 with Martin Marietta Energy Systems.

\section{REFERENCES}

1. ASTM C 1161-90 "Standard Test Method for Flexural Strength of Advanced Ceramics at Ambient Temperature," Annual Book of ASTM Standards, Vol. 15.01, 333-339, (1990).
2. "Fractography and Characterization of Fracture Origins in Advanced Structural Ceramics," MIL-HDBK-790, (July, 1992).

3. Batdorf, S. B. and Crose, J. G., "A Statistical Theory for the Fracture of Brittle Structures Subjected to Nonuniform Polyaxial Stresses", Journal of Applied Mechanics, Vol.41, No.2, pp 459-464, (June1974).

4. Batdorf, S. B.; and Heinisch, H. L., Jr. "Weakest Link Theory Reformulated for Arbitrary Fracture Criterion," Journal of the American Ceramic Society, Vol. 61, No.7-8, pp. 355-358, (July-Aug. 1978).

5. Batdorf, S. B., "Fundamentals of the Statistical Theory of Fracture", Fracture Mechanics of Ceramics, Vol. 3, eds., Bradt, R. C., Hasselman, D. P. H. and Lange, F. F., Plenum Press, New York, pp 1-30, (1978).

6. Shetty, D.K., Mixed-Mode Fracture Criteria for Reliability Analysis and Design with Structural Ceramics. Journal of Engineering for Gas Turbines and Power, Vol. 109, No. 3, pp. 282-289 (July 1987).

7. Nemeth, N. N., Manderscheid, J. M., Gyekenyesi, J. P., "Ceramic Analysis and Reliability Evaluation of Structures (CARES)", NASA TP-2916, Aug.1990.

8. D. W. Richerson, Modern Ceramic Engineering, Marcel Dekker, New York and Basel, pp. 260-73, (1982).

9. Powers, L. M., Starlinger, A., Gyekenyesi, J. P., "Ceramic Component Reliability With the Restructured NASA/CARES Computer Program", NASA TM-105856, (Sept. 1992).

10. Shetty, D. K., Rosenfield, A. R., Bansal, G. K., and Duckworth, W. H., "Biaxial Flexure Test for Ceramics", Journal of the American Ceramic Society, Vol. 59, No. 12, pp. 1193-1197, 1980. 
TABLE 1.-SUMMARY OF STRENGTH DATA

\begin{tabular}{|c|c|c|c|c|c|}
\hline $\begin{array}{c}\text { Grinding } \\
\text { Angle }\end{array}$ & $\begin{array}{c}\text { Number } \\
\text { Tested }\end{array}$ & $\begin{array}{c}\text { Range } \\
(\mathrm{MPa})\end{array}$ & $\begin{array}{c}\text { Average }^{1} \\
(\mathrm{MPa})\end{array}$ & $\begin{array}{c}\text { Characteristic } \\
\text { Strength (MPa) }\end{array}$ & $\begin{array}{c}\text { Weibull }^{2} \\
\text { Modulus }\end{array}$ \\
\hline$\frac{\text { As-Ground }}{0^{\circ}}$ & 36 & $266-458$ & $356 \pm 47$ & 377 & 8.2 \\
30 & 34 & $271-400$ & $334 \pm 32$ & 348 & 11.6 \\
45 & 32 & $267-392$ & $327 \pm 35$ & 341 & 10.5 \\
60 & 31 & $273-331$ & $306 \pm 17$ & 314 & 21.3 \\
90 & 35 & $246-308$ & $276 \pm 14$ & 282 & 19.8 \\
& & & & & \\
Annealed & & & & & \\
$0^{\circ}$ & 36 & $265-465$ & $362 \pm 51$ & 384 & 8.3 \\
90 & 36 & $222-481$ & $357 \pm 56$ & 380 & 6.8 \\
\hline
\end{tabular}

${ }^{1}$ Average \pm one standard deviation.

${ }^{2}$ Maximum likelihood estimator.

TABLE 2.-SUMMARY OF FAILURE ORIGINS

\begin{tabular}{|c|c|c|c|c|c|}
\hline $\begin{array}{c}\text { Grinding } \\
\text { Angle }\end{array}$ & $\begin{array}{c}\text { Surface and } \\
\text { Near Surface } \\
\text { Agglomerates }\end{array}$ & $\begin{array}{c}\text { Volume } \\
\text { Agglomerates }\end{array}$ & $\begin{array}{c}\text { Machining } \\
\text { Damage }\end{array}$ & $\begin{array}{c}\text { Hybrid } \\
\text { Flaws }\end{array}$ & $\begin{array}{c}\text { Not } \\
\text { Identifiable }\end{array}$ \\
\hline As-Ground & & 1 & 0 & 3 & 0 \\
$0^{\circ}$ & 31 & 1 & 0 & 4 & 0 \\
30 & 30 & 0 & 9 & 2 & 0 \\
45 & 21 & 0 & 17 & 3 & 0 \\
60 & 11 & 0 & 33 & 2 & 0 \\
90 & 0 & 3 & 0 & 0 & 1 \\
Annealed & 32 & 3 & 2 & 0 & 0 \\
\hline $0^{\circ}$ & 31 & & & & \\
90 & & 3 & & & \\
\hline
\end{tabular}

TABLE 3.-SUMMARY OF STRENGTH DATA FOR MODEL VERIFICATION

\begin{tabular}{|c|c|c|c|c|c|}
\hline $\begin{array}{c}\text { Grinding } \\
\text { Angle }\end{array}$ & $\begin{array}{c}\text { Number } \\
\text { Tested }\end{array}$ & $\begin{array}{c}\text { Range } \\
(\mathrm{MPa})\end{array}$ & $\begin{array}{c}\text { Average }^{1} \\
(\mathrm{MPa})\end{array}$ & $\begin{array}{c}\text { Characteristic }_{\text {Strength }^{2}(\mathrm{MPa})} \\
\text { As-Ground }\end{array}$ & $\begin{array}{c}\text { Weibull } \\
\text { Modulus }\end{array}$ \\
$\begin{array}{c}90^{\circ} \\
\text { (3-point) }\end{array}$ & 31 & $231-364$ & $303 \pm 37$ & 319 & $\begin{array}{c}9.6 \\
(7.3-12.6)\end{array}$ \\
90 & 31 & $172-327$ & $249 \pm 39$ & $\begin{array}{c}265 \\
(254-277)\end{array}$ & $\begin{array}{c}7.4 \\
(5.6-9.0)\end{array}$ \\
(4-point) & & $142-250$ & $206 \pm 28$ & 218 & $\begin{array}{c}8.5 \\
(6.6-11.0)\end{array}$ \\
\hline
\end{tabular}

${ }^{1}$ Average \pm one standard deviation.

${ }^{2}$ Maximum likelihood estimator. Values in parentheses are the $95 \%$ confidence interval. 

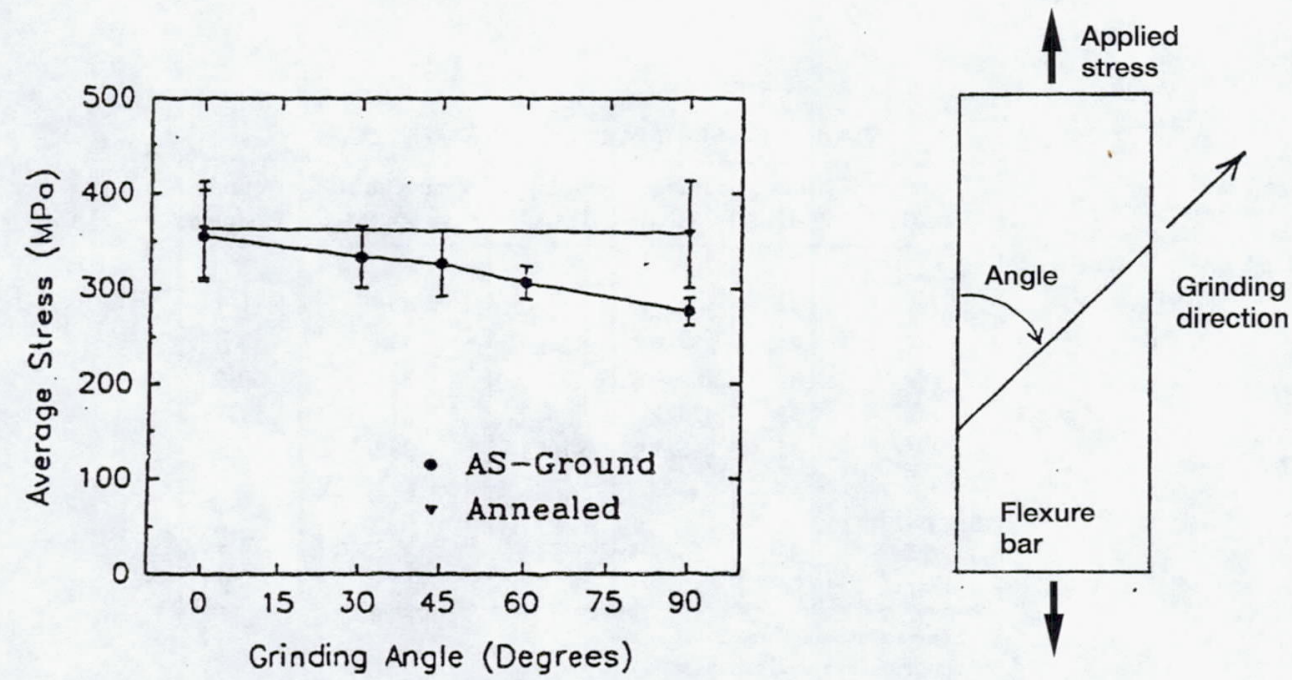

Figure 1.-Average four-point flexure strength as a function of grinding angle. Error bars are tone standard deviation.
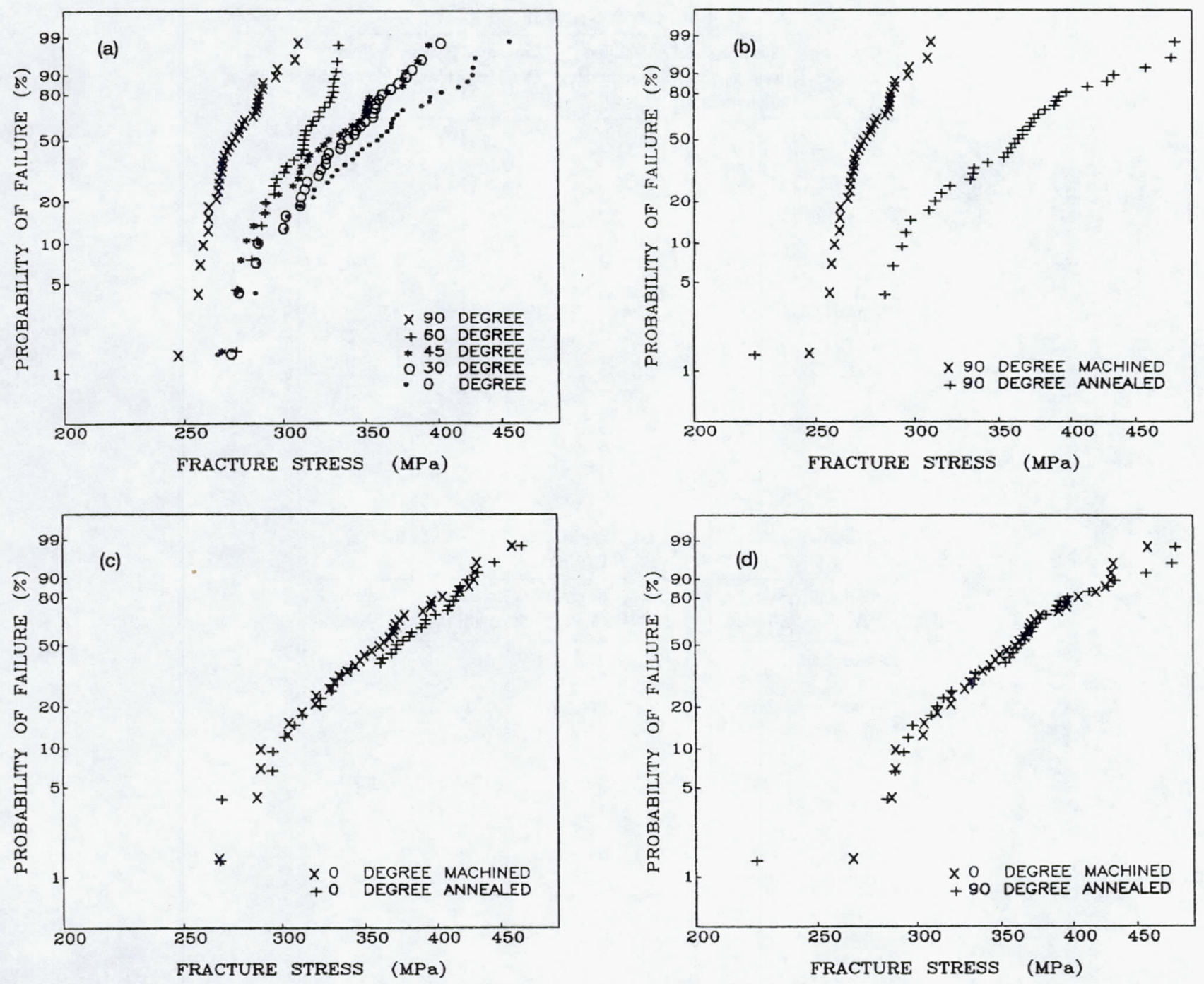

Figure 2.-Weibull plots of the fracture stresses for (a) all as-ground specimens, (b) $90^{\circ}$ annealed and as-ground specimens, (c) $0^{\circ}$ annealed and as-ground specimens and (d) $90^{\circ}$ annealed and $0^{\circ}$ as-ground specimens. 


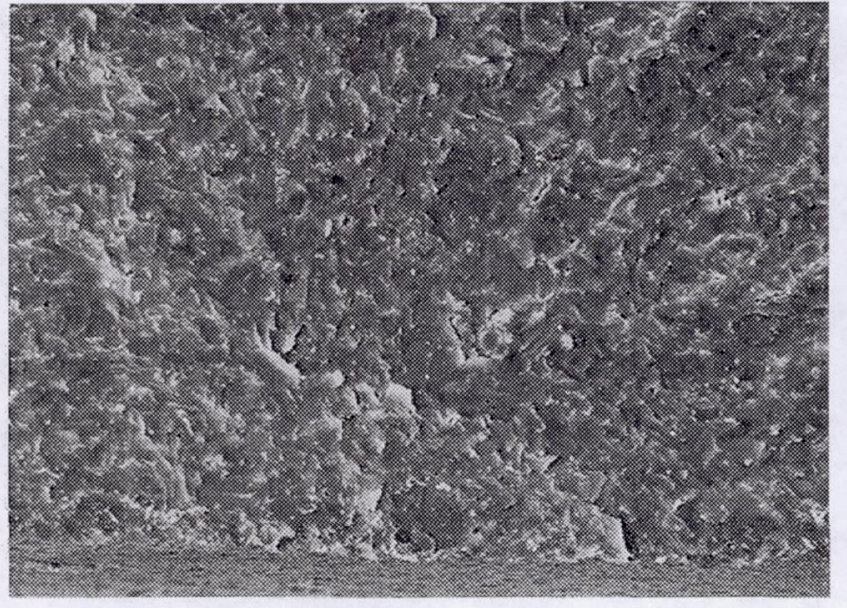

(a)

$50 \mu \mathrm{m}$

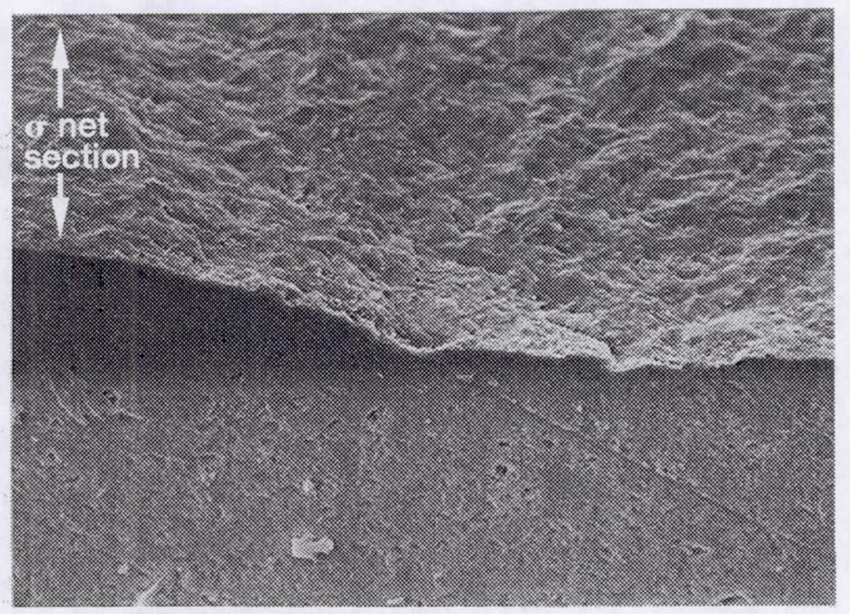

(b)

$50 \mu \mathrm{m}$

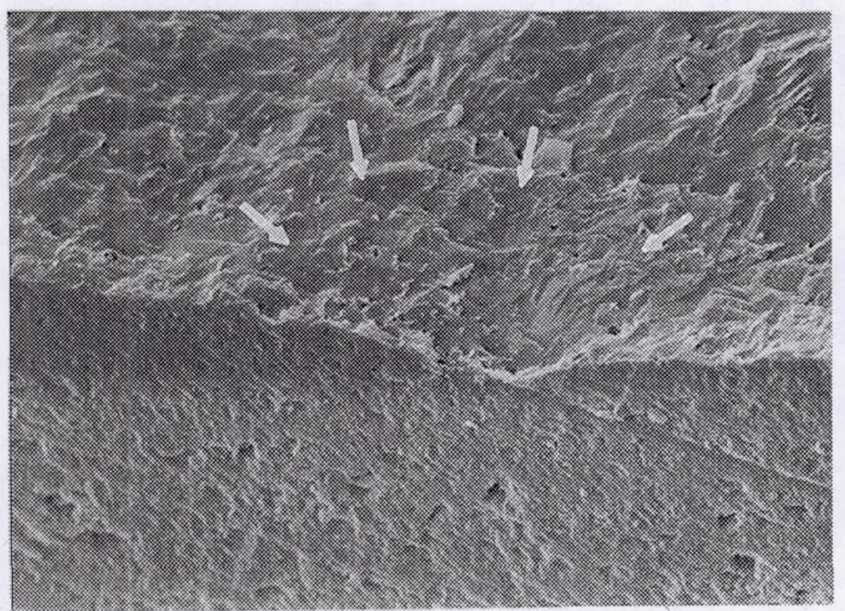

(c)

$20 \mu \mathrm{m}$

Figure 3.-Failure origins showing (a) surface connected processing agglomerate, (b) $30^{\circ}$ tilt, machining crack, mirror and machining scratch (c) $30^{\circ}$ tilt, machining crack detail.

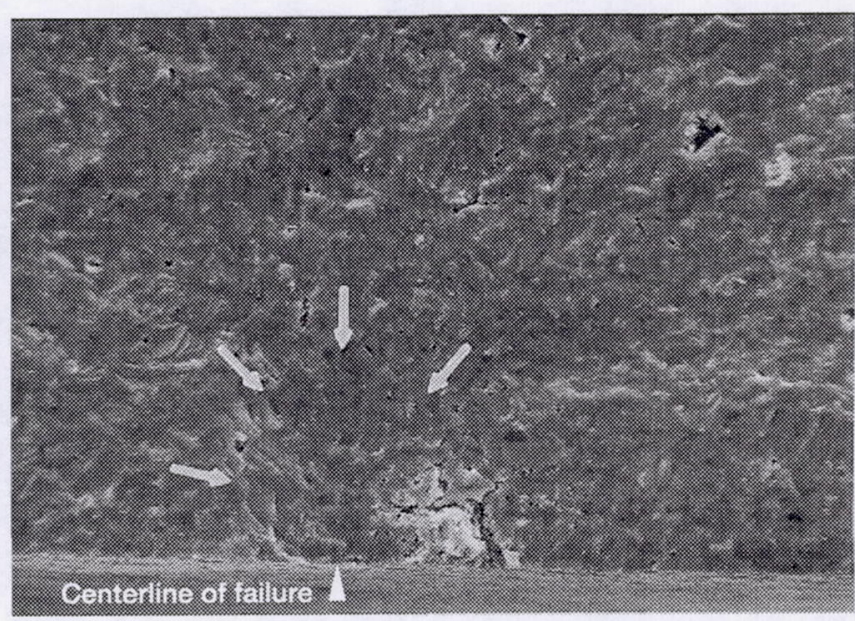

(a)

$50 \mu \mathrm{m}$

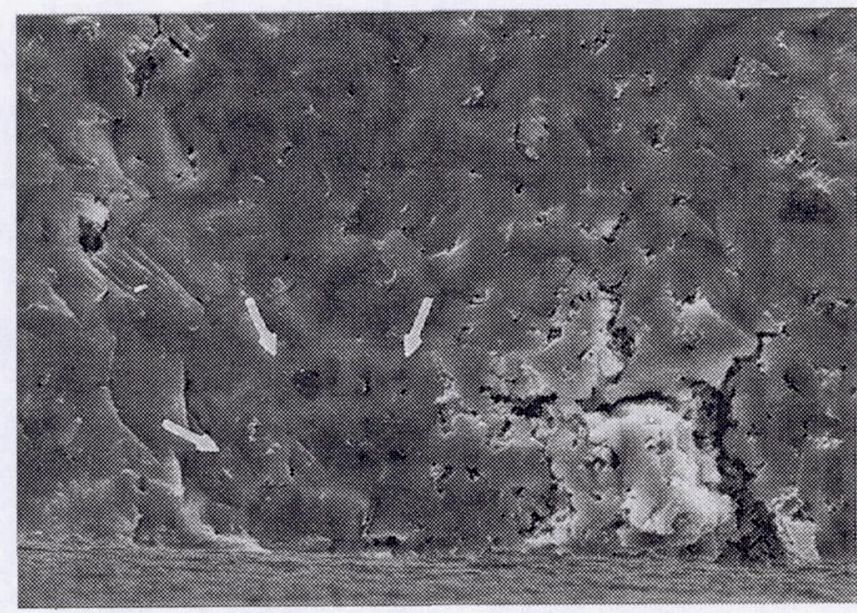

(b)

$20 \mu \mathrm{m}$

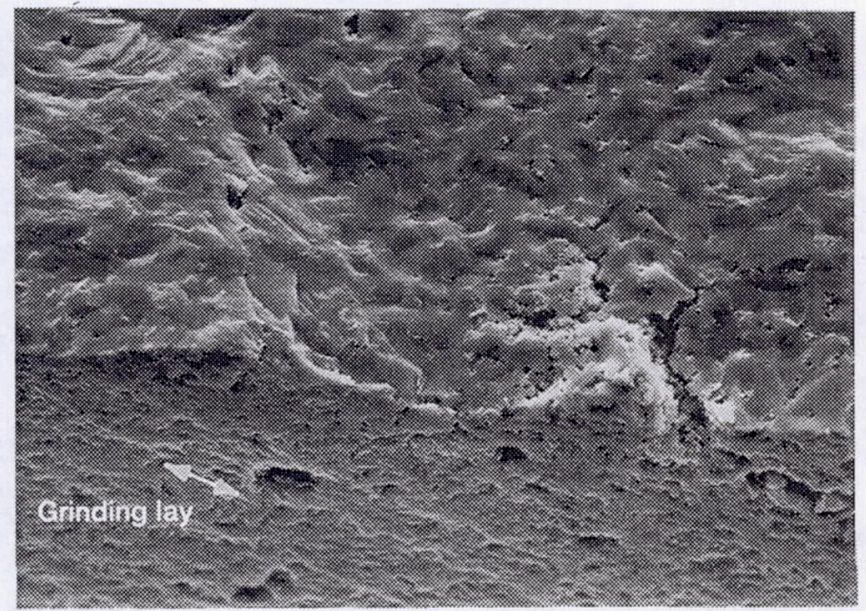

(c)

$50 \mu \mathrm{m}$

Figure 4.-Hybrid flaw and detail: (a) river marks, machining crack and agglomerate (b) machining crack; and (c) grinding lay. 

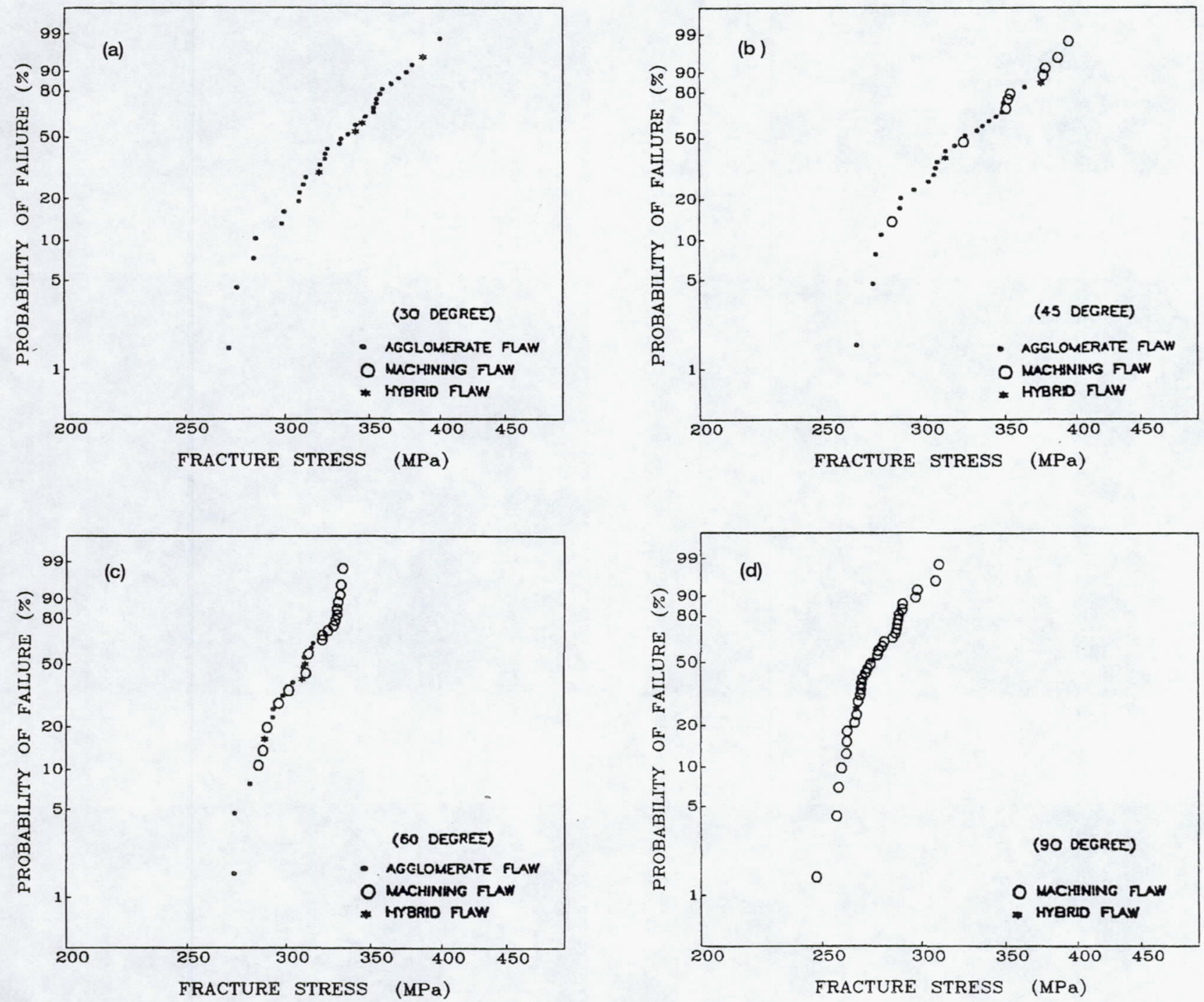

Figure 5.-Weibull plots of the fracture stresses for $30,45,60$ and $90^{\circ}$ as-ground specimens showing the different failure sources. 

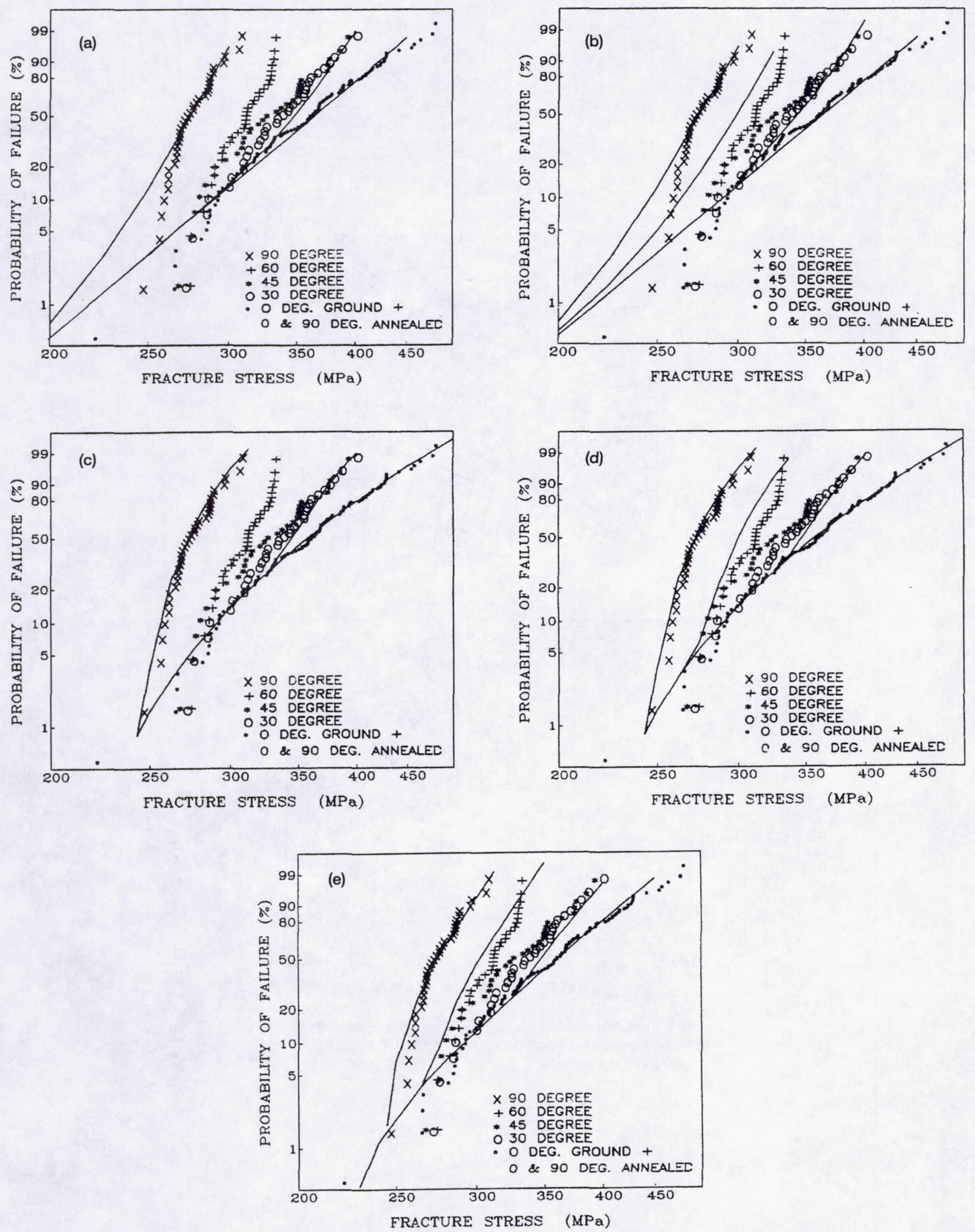

Figure 6.- Experimental data and (a) two parameter shear insensitive model, (b) two parameter shear sensitive model, (c) three parameter shear insensitive model, (d) three parameter shear sensitive model and, (e) two parameter shear sensitive model with a truncation load. In these plots the value of $\bar{C}$ ranges between 1.0 and 1.05 (or approximately 1.0 ). 

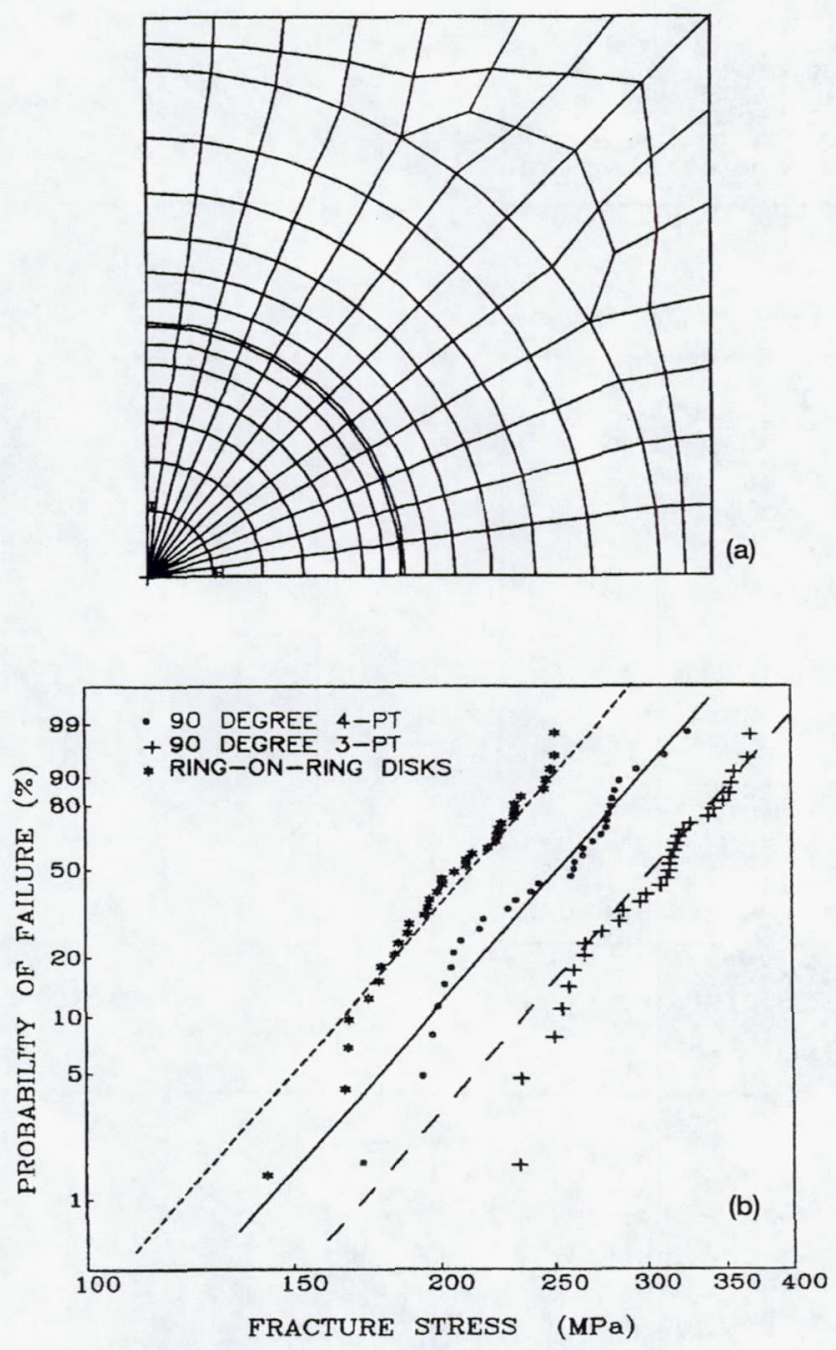

Figure 7.-(a) FEM mesh and (b) experimental data with MLE fit (solid line) and predictions based on a two parameter model (dashed lines). 
Public reporting burden for this collection of information is estimated to average 1 hour per response, including the time for reviewing instructions, searching existing data sources, gathering and maintaining the data needed, and completing and reviewing the collection of information. Send comments regarding this burden estimate or any other aspect of this collection of information, including suggestions for reducing this burden, to Washington Headquarters Services, Directorate for Information Operations and Reports, 1215 Jefferson Davis Highway, Suite 1204, Arlington, VA 22202-4302, and to the Office of Management and Budget, Paperwork Reduction Project (0704-0188), Washington, DC 20503.

\begin{tabular}{|l|c|c|}
\hline 1. AGENCY USE ONLY (Leave blank) & $\begin{array}{c}\text { 2. REPORT DATE } \\
\text { February } 1995\end{array}$ & $\begin{array}{r}\text { 3. REPORT TYPE AND DATES COVERED } \\
\text { Technical Memorandum }\end{array}$ \\
\hline
\end{tabular}

\section{TITLE AND SUBTITLE}

5. FUNDING NUMBERS

Reliability Analysis of Uniaxially Ground Brittle Materials

6. $\operatorname{AUTHOR}(\mathrm{S})$

Jonathan A. Salem, Noel N. Nemeth, Lynn M. Powers, and Sung R. Choi

WU-505-63-5B

\section{PERFORMING ORGANIZATION NAME(S) AND ADDRESS(ES)}

8. PERFORMING ORGANIZATION REPORT NUMBER

National Aeronautics and Space Administration Lewis Research Center

Cleveland, Ohio 44135-3191

E-9441

9. SPONSORING/MONITORING AGENCY NAME(S) AND ADDRESS(ES)

10. SPONSORING/MONITORING AGENCY REPORT NUMBER

National Aeronautics and Space Administration

Washington, D.C. 20546-0001

NASA TM-106852

\section{SUPPLEMENTARY NOTES}

Prepared for the Turbo Expo 1995 sponsored by the American Society of Mechanical Engineers, Houston, Texas, June 5-8, 1995. Jonathan A. Salem and Noel N. Nemeth, NASA Lewis Research Center; Lynn M. Powers and Sung R. Choi, Cleveland State University, Department of Civil Engineering, Cleveland, Ohio 44115. Responsible person, Noel N. Nemeth, organization code 5250, (216) 433-3215.

12a. DISTRIBUTION/AVAILABILITY STATEMENT

Unclassified - Unlimited

Subject Category 39

This publication is available from the NASA Center for Aerospace Information, (301) 621-0390.

13. ABSTRACT (Maximum 200 words)

The fast fracture strength distribution of uniaxially ground, alpha silicon carbide was investigated as a function of grinding angle relative to the principal stress direction in flexure. Both as-ground and ground/annealed surfaces were investigated. The resulting flexural strength distributions were used to verify reliability models and predict the strength distribution of larger plate specimens tested in biaxial flexure. Complete fractography was done on the specimens. Failures occurred from agglomerates, machining cracks, or hybrid flaws that consisted of a machining crack located at a processing agglomerate. Annealing eliminated failures due to machining damage. Reliability analyses were performed using two and three parameter Weibull and Batdorf methodologies. The Weibull size effect was demonstrated for machining flaws. Mixed mode reliability models reasonably predicted the strength distributions of uniaxial flexure and biaxial plate specimens.

\section{SUBJECT TERMS}

Grinding damage; Reliability; Ceramic; Design

\begin{tabular}{|c|c|}
\hline & $\begin{array}{c}\text { 15. NUMBER OF PAGES } \\
14\end{array}$ \\
\cline { 2 - 2 } & $\begin{array}{c}\text { 16. PRICE CODE } \\
\text { A03 }\end{array}$ \\
\hline $\begin{array}{c}\text { 19. SECURITY CLASSIFICATION } \\
\text { OF ABSTRACT } \\
\text { Unclassified }\end{array}$ & $\begin{array}{l}\text { 20. LIMITATION OF ABSTRACT } \\
\end{array}$
\end{tabular}

